\title{
Towards the Improvement of the Computer Network of Mosul University Using (OPNET) Software
}

\author{
Mohammed Basheer Abdullah* \\ Dr. A.I. A. Jabbar*
}

*Electrical Eng. Dept., College of Engineering, Univ. of Mosul.

\begin{abstract}
Mosul University network which covers most of its departments and colleges has been implemented in a star topology using fiber optic cables and Cisco switches. In order to participate in optimizing the network performance by minimizing broadcast and collision domains, a proposed network (as an example) for the Engineering College based on VLAN technique has been developed using the network simulator software (OPNET IT GURU). The suggested model could be applied to other colleges. The results being obtained represent the optimum possible improvements in terms of node delay, throughput and minimizing unnecessary traffic to avoid network congestion.
\end{abstract}

Keywords: Network Simulation, OPNET, VLAN, Switch

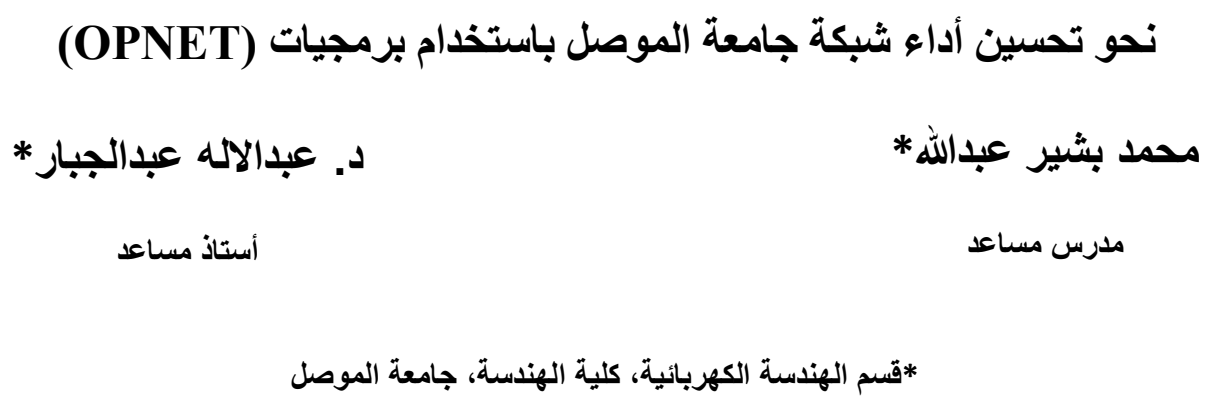

الخلاصة 
أنشأت شبكة جامعة الموصل التي تغطي الآن معظم كلياتها و أقسامها على طبو غر افيـة

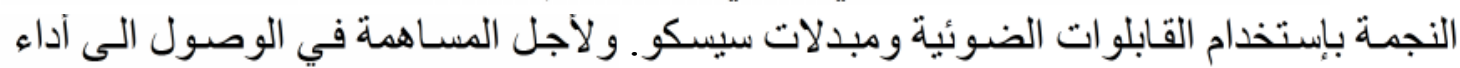

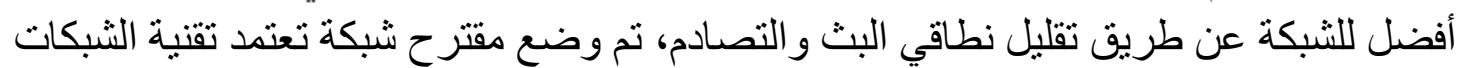

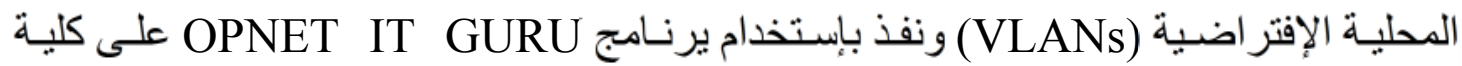

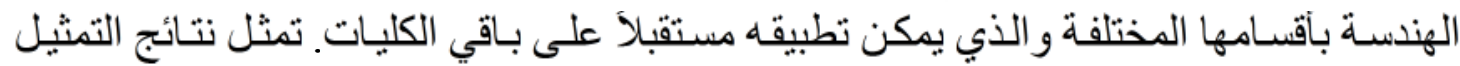

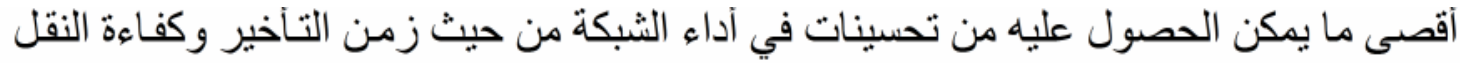
و انخفاض احتمالية حدوث إختناقات في سير الحزم خلال الثبكة. 


\section{Introduction:}

Simulation is becoming an increasingly popular method for network performance analysis. Software simulator is a valuable tool especially for recent networks with complex architectures and topologies. A typical simulator can provide the programmer with the necessary information of how to control and manage the performance of a computer network. Functions and protocols are described either by finite state machine, native programming code, or a combination of the two [1]. Network simulators have developed since they first appeared as performance, management and prediction tools. They are normally used as network management tools, for which packet level analysis is not commonly employed. The most known network simulator OPNET (OPNET stands for OPtimum NETwork performance) from OPNET Technologies Inc. [2] is superior compared with other network simulation packages in terms of user interface, flexibility, scalability, and accuracy $[3,4]$.

A backbone network in the University of Mosul has been established recently through the fiber optic mesh which is available around the campus of the university. Figure (1) shows a schematic diagram of the existing network. The figure declares that the topology is stared configuration around a core switch (Cisco 6509) while the colleges and departments are accommodated with Cisco switches (2950, 3750). The numbers encircled represent the departments of the college of Engineering, for more details see Figure (2). This network provides the university with Internet services to all university buildings and will help in adopting distributed database systems to facilitate administration and other scientific services. It is obvious that simulating the campus network will highly aid its practical implementation. This will also help in testing new ideas and carry out performance related studies without going into a series of "trial and error" hardware implementations. It is obvious that the simulation results represent the maximum possible performance that can be expected.

The concept of virtual local area network (VLAN) helps in segregating a large switched network with a single broadcast domain into multiple limited broadcast domains. Broadcast traffic consumes a lot of 
the bandwidth. Another benefit of VLAN is to provide a better security by isolating computers connected to the same network according to their departments' function [5].

OPNET's IT Guru is applied in the performance study of this network; it provides a comprehensive development environment for the specification simulation and performance analysis of computer networks.

\section{The proposed network configuration:}

Figure (2) shows a satellite picture of the campus of Mosul University together with the fiber optic cable routes. This study is focusing on the college of engineering because it consists of several departments and can be considered as a good example of studying the network and the design can be repeated to other colleges easily. The 


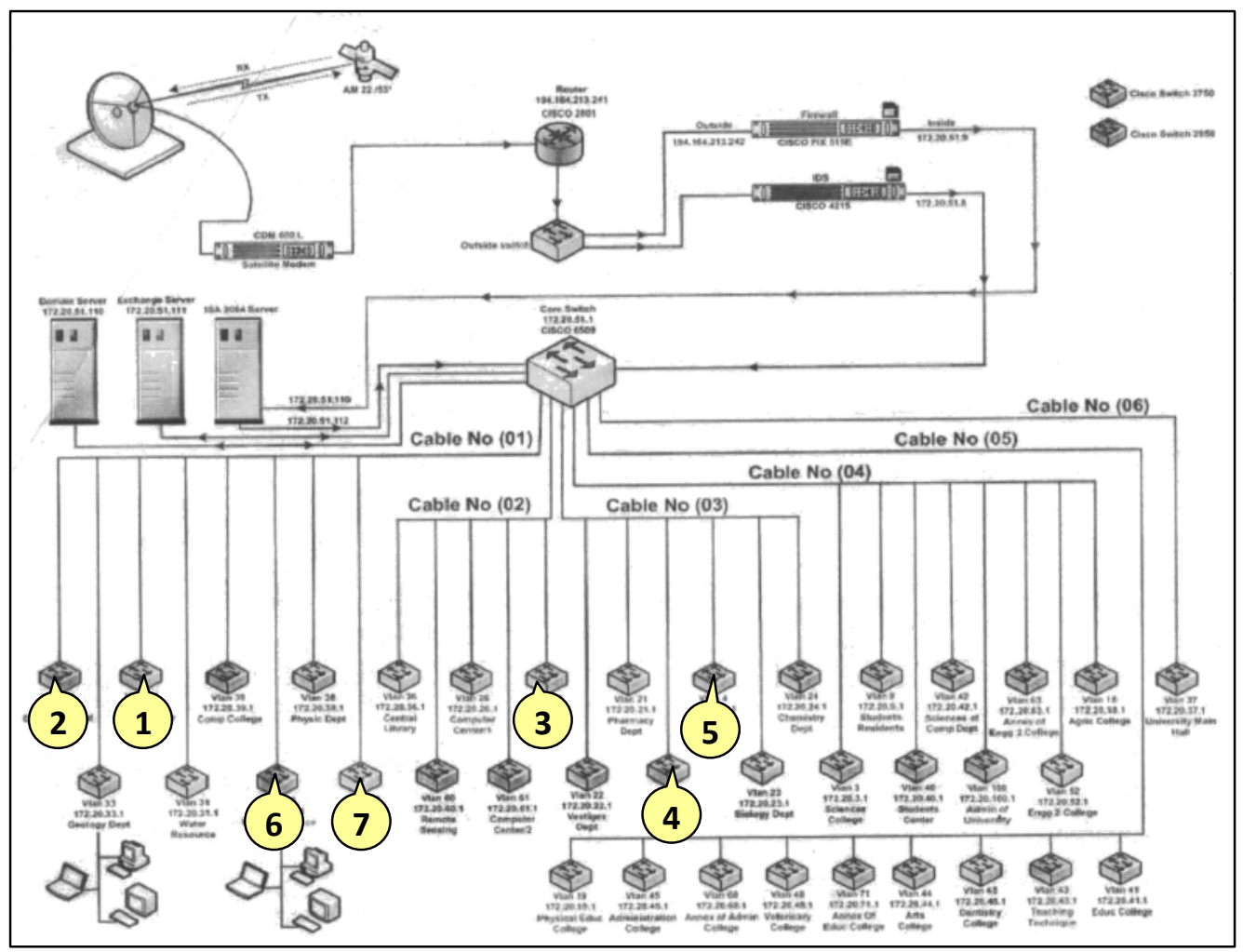

Figure (1). Schematic diagram of existing Mosul University network.

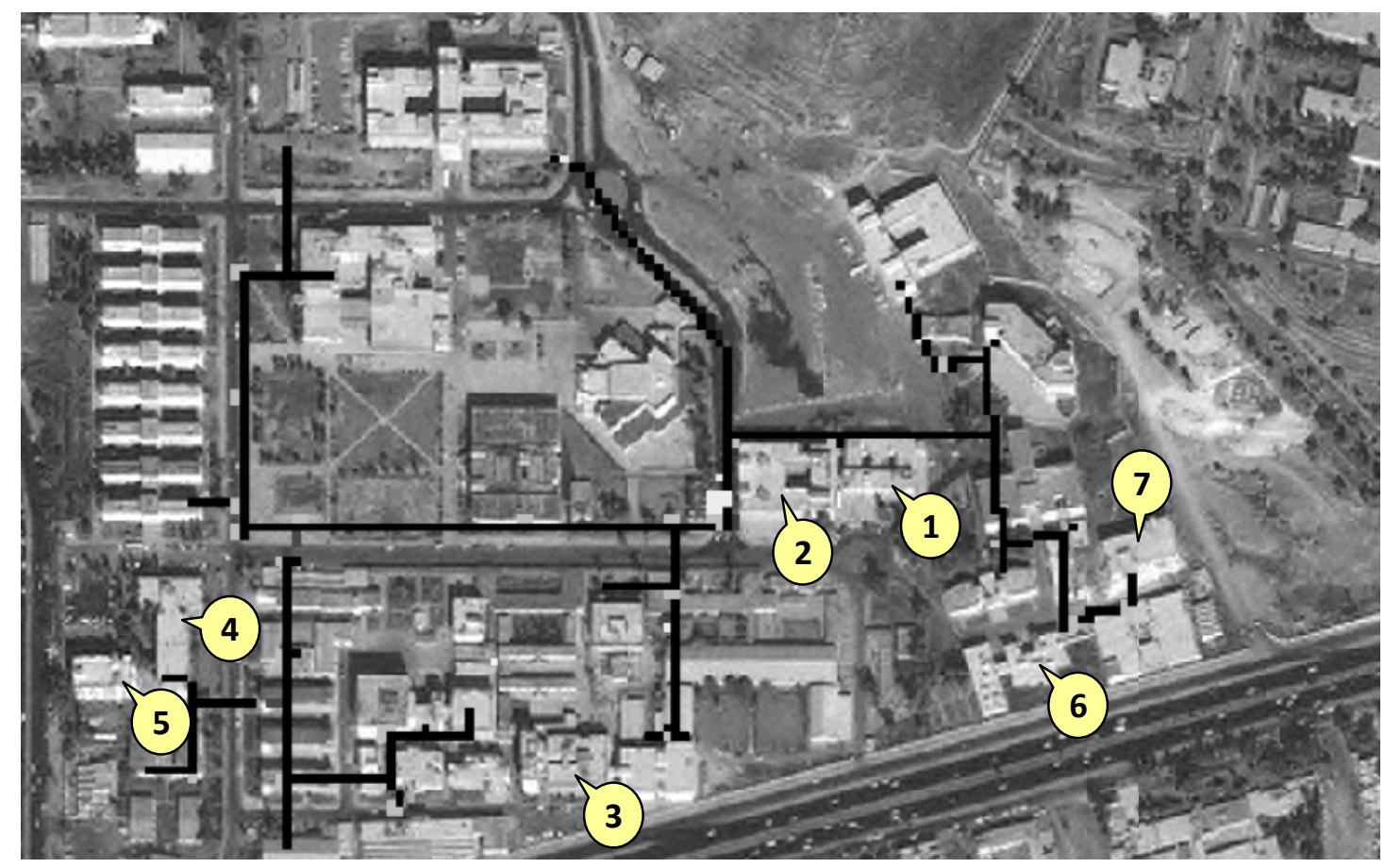

Figure (2). A satellite picture of the Mosul University campus, the bold lines represent the fiber cable routes between the different buildings. 
numbers which are shown on the figure represent the locations of the buildings of the college of engineering, they are:

1. The Deanery Building.

2. The Electrical Engineering Department.

3. The Mechanical Engineering Department.

4. The Civil Engineering Department.

5. The Architecture Engineering Department.

6. The Water Resources Engineering Department.

7. The Computer Engineering Department.

Figure (3) shows the application of the above campus to OPNET IT GURU along with the dimensions of the network in meters. Each department has a central VLAN switch that connects some important individual computers and other department LANs with the main VLAN switch in the deanery building. From the functional point of view, the proposed network provides the following services:

1. Administration.

2. Registration.

3. Higher studies.

4. Financial.

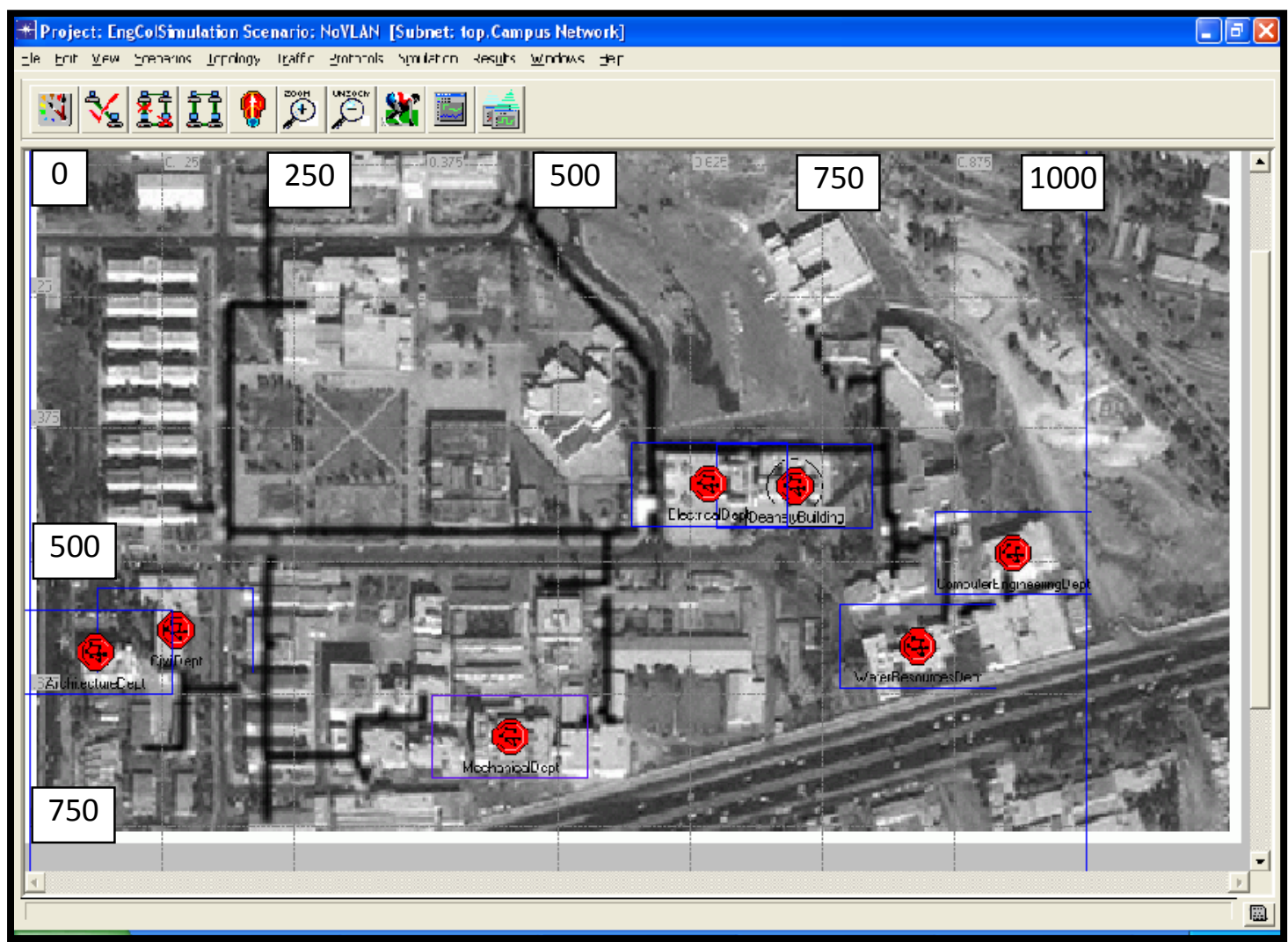

Figure (3) The College of engineering model as applied to OPNET IT GURU. 
Table (1) shows a lockup table for the VLAN identification of the four services. The VLAN membership definition is based upon switch port only which is also called static VLAN. This definition provides security, minimum delay, and it is the only definition that IT GURU (OPNET software) permits.

\section{Model Assumptions:}

1. Packet (payload data) length is uniformly distributed within the range (46-1500) byte.

2. Traffic load is inversely proportional to the packets inter-arrival time which has a constant distribution.

3. Minimum inter-arrival time of packets is (0.01) sec which correspond to $100 \%$ offered load and maximum inter-arrival time is (0.1) sec which correspond to $10 \%$ of offered load. 
4. The computers within a building are interconnected together using UTP (Cat. 5) cables, while the trunk links are of fiber optic cable type.

5. Internet services can be supplied from more than single ISP.

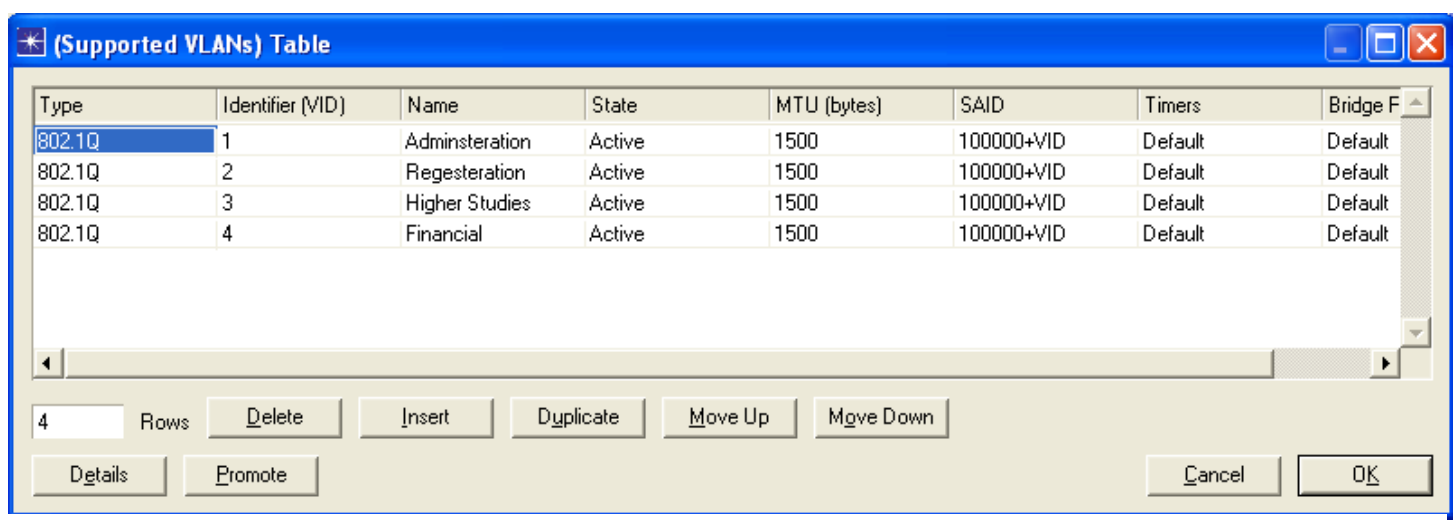

Table(1). Lookup table for VLANs identification.

\section{The Simulation of the Proposed Network:}

Model creation using OPNET IT GURU is straightforward. Each department is modeled as a subnet that contains a VLAN switch with some computers and other LANs that represent the department labs networks. The links being used inside each subnet of the access link type (i.e. VLAN unaware link). The deanery building contains the main VLAN switch; it connects the VLAN switches of the departments through trunk VLAN links. The computers and servers of the denary are interconnected through the access links of the main switch. Connecting the college of engineering network to the Internet is made through a router and firewall. Figure (4) shows the details of the deanery building subnet.

According to the OPNET software performance, each node (computer or network device) in the simulation model has a set of attributes (parameters) which can be configured through the node attributes editor. They describe the behavior of the node throughout the simulation. As an example figure (5) shows the attributes setting of the main VLAN switch and one of the computers in the deanery building. 


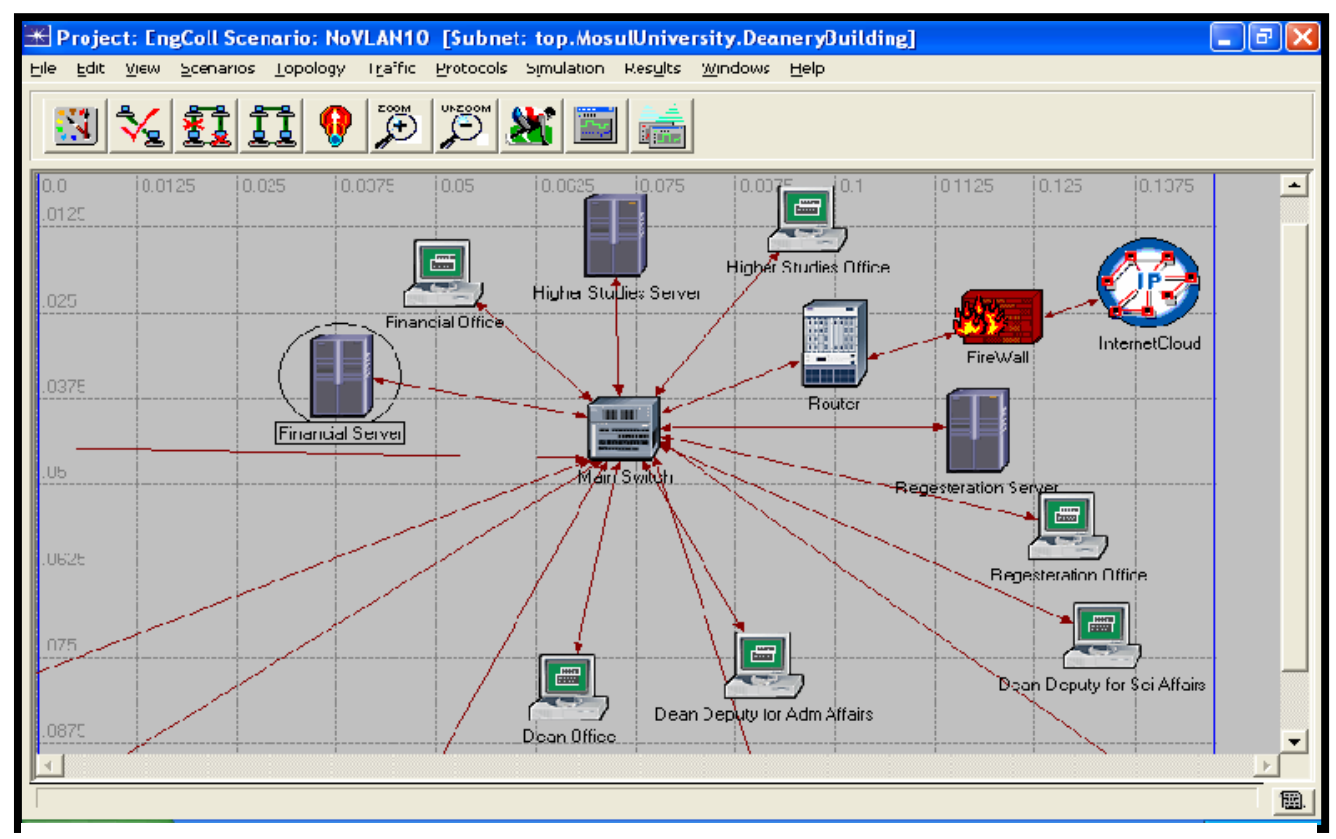

Figure (4). Details of the deanery subnet.

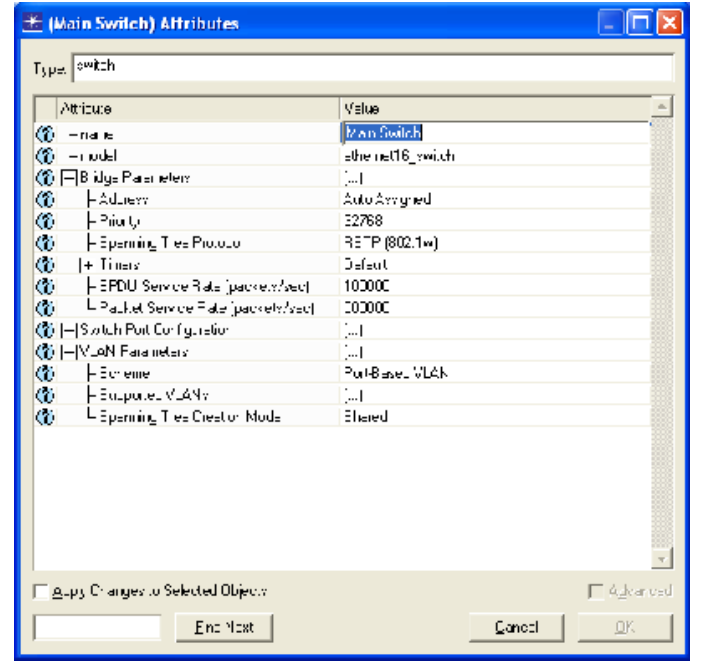

(a)

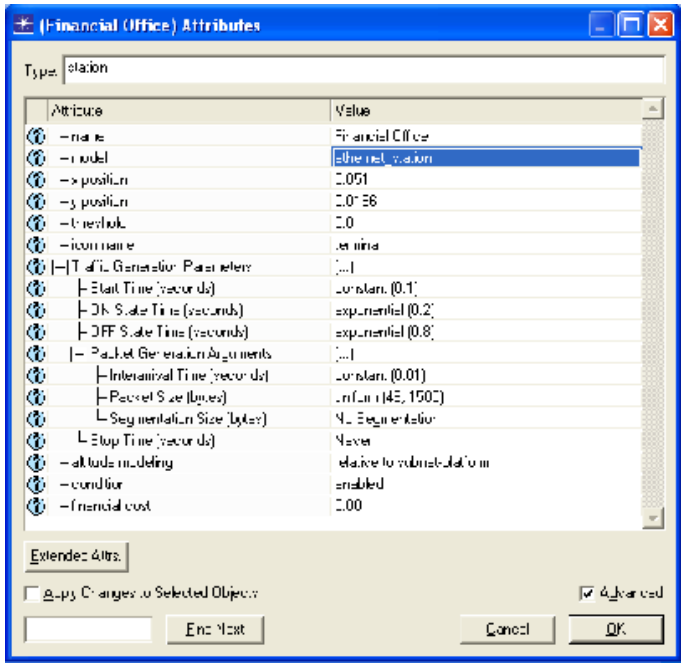

(b)

Figure (5) Node attributes setting editor. (a) The main VLAN switch in the deanery building. (b) The Financial office computer. 
After setting the attributes of the nodes, it is required to select the needed statistics for the simulation, this is achieved through the "choose result" window as shown in figure (6). OPNET IT GURU provides a big library of statistics classified as follows:

1. Global statistics: These statistics are recorded for every node in the model.

2. Node statistics: These statistics are recorded for selected nodes in the model

3. Link statistics: These statistics are concerning the selected links in the model.

In this study and in order to demonstrate the effect of using VLAN concept the following statistics are selected: node delay, traffic forwarded at the core switch, and throughput for different offered loads.

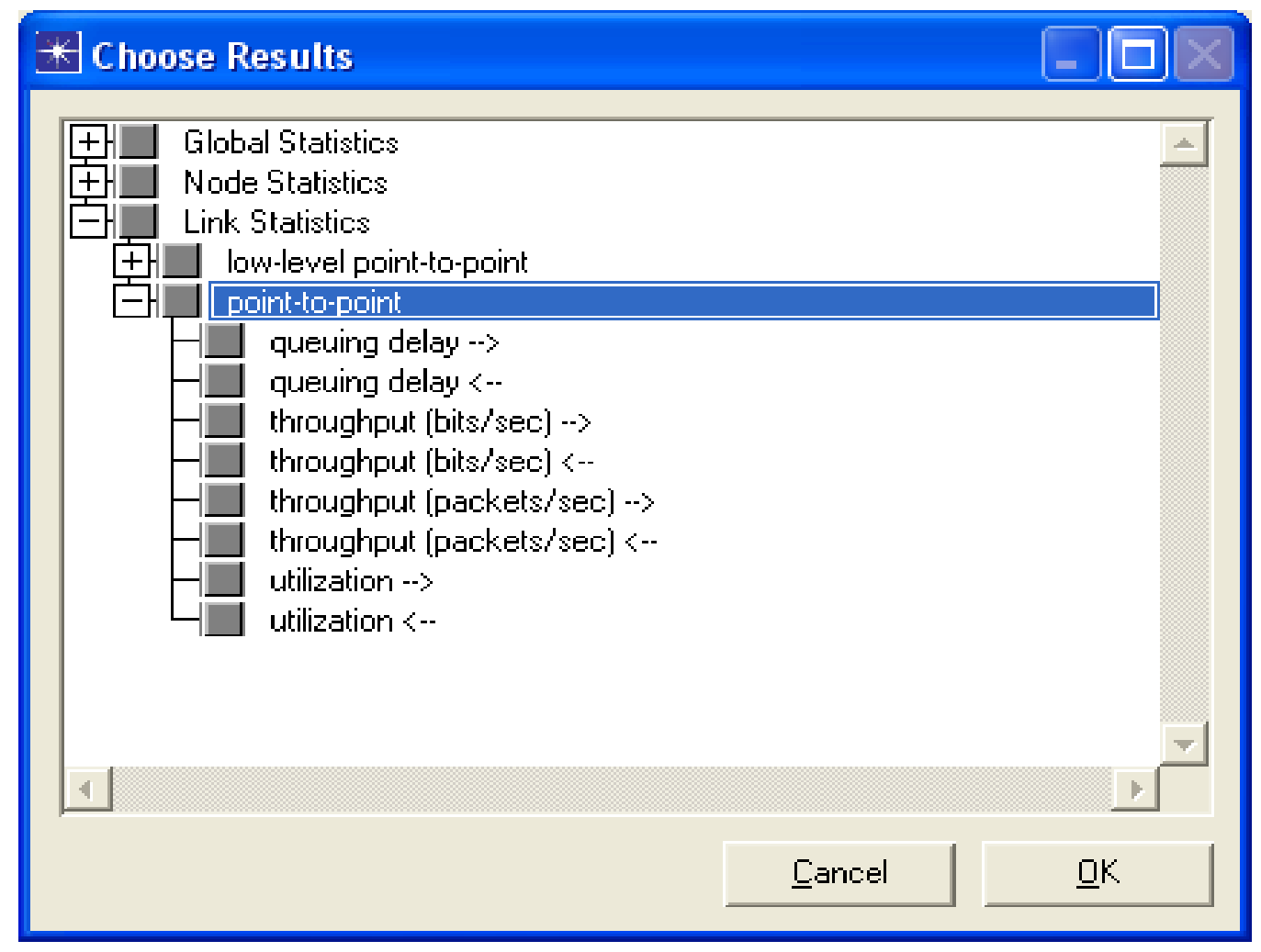

Figure (6). The needed statistics are selected through this window. 
From the simulation point of view, the effect of various offered loads on the performance of the existing network is studied using many scenario commands and instructions. This can be achieved by varying the packet generation attributes for all computers in the model. On the other hand, another set of scenarios are applied where the VLAN attributes of the switches is set to the same services described in table (1). Figure (7) shows the way of accessing scenarios which are applied in this project.

Figure (8) shows a flow chart that describes how to precede the

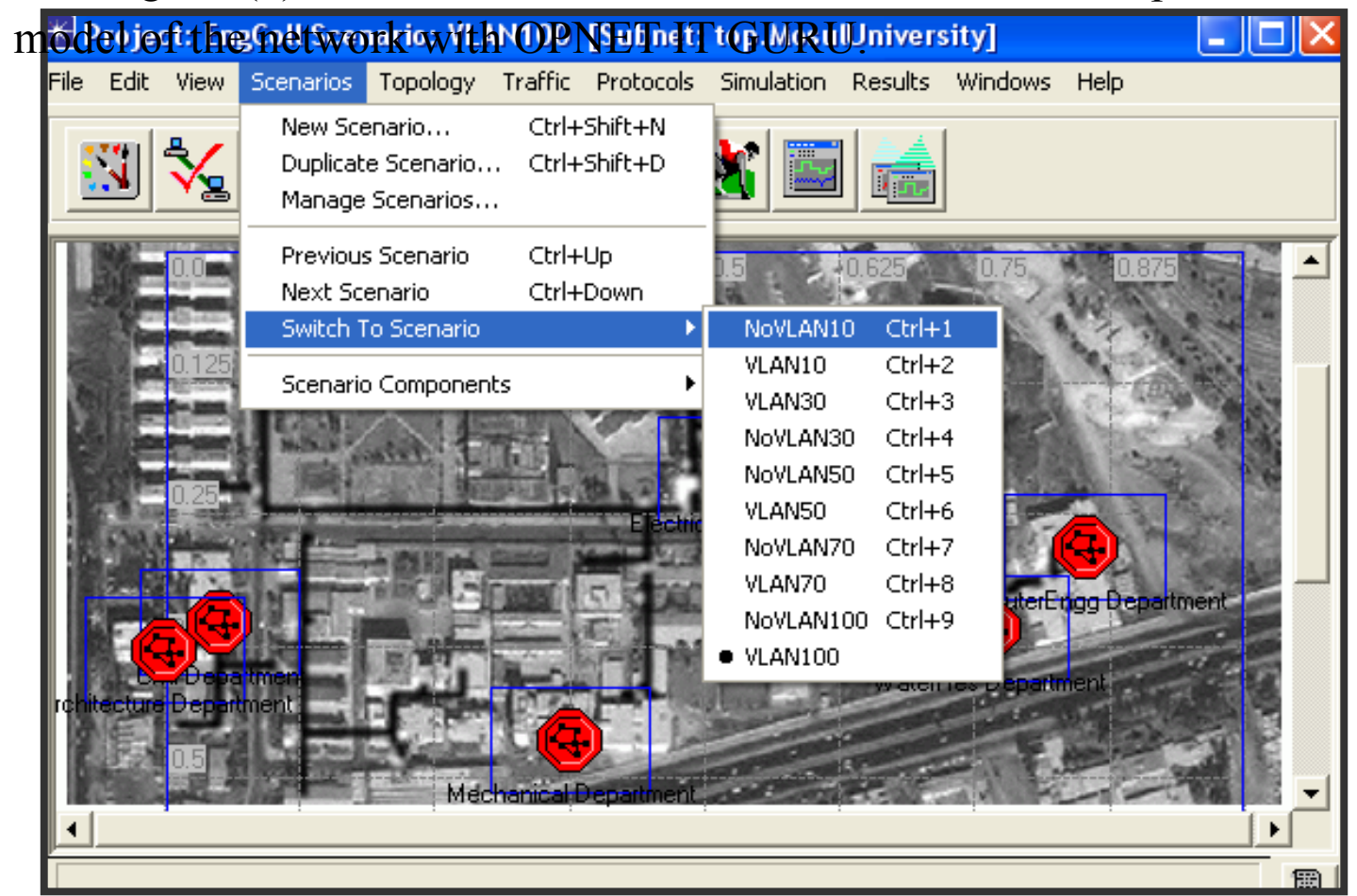

Figure (7) Different scenarios were made for different percentage of offered loads. 


\section{Results and Discussion:-}

Figure (9) shows the simulation result of the traffic forwarded for all the scenarios being applied. It is obvious that the results being obtained represent the instantaneous variation of the statistic as a function of the simulation (actual) time. Figure (10) shows the relationship between the traffic forwarded and the offered load, the figure reveals the fact that the performance with VLAN improves the results as compared with the case of the existing network.

Node delay is an important factor in determining the performance of any network, it measures the time required to get the packet from source to destination. Figure (11) shows the relationship between node delay and offered load for the existing and proposed networks. The use of VLAN technique reduced node delay from $(273 \mu \mathrm{Sec}$.) to nearly $(200 \mu \mathrm{Sec}$.) for the cases of high offered loads.

Another important factor related to the performance of networks is throughput. This criteria measures the information rate of a channel in a 
network. Figure (12) shows the relationship between throughput and offered load. A big improvement in maximum possible throughput is recognized when using VLAN concept. Finally, the Internet traffic effect on the network performance is shown in figure (13). Again the application of VLAN switches shows a better network performance as compared with the existing network. 


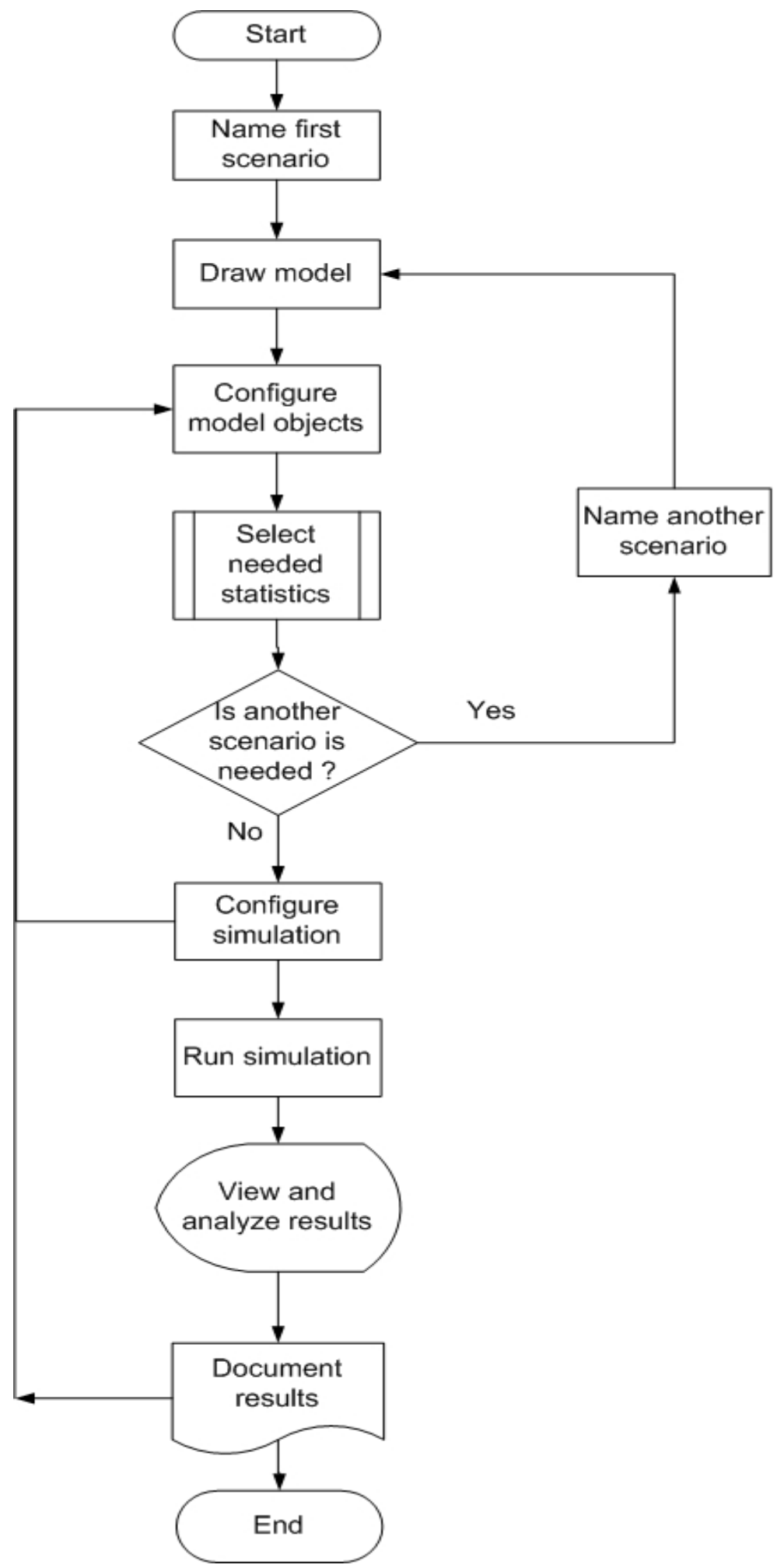

Figure (8) Flow chart describes network modeling in OPNET ITGURU. 


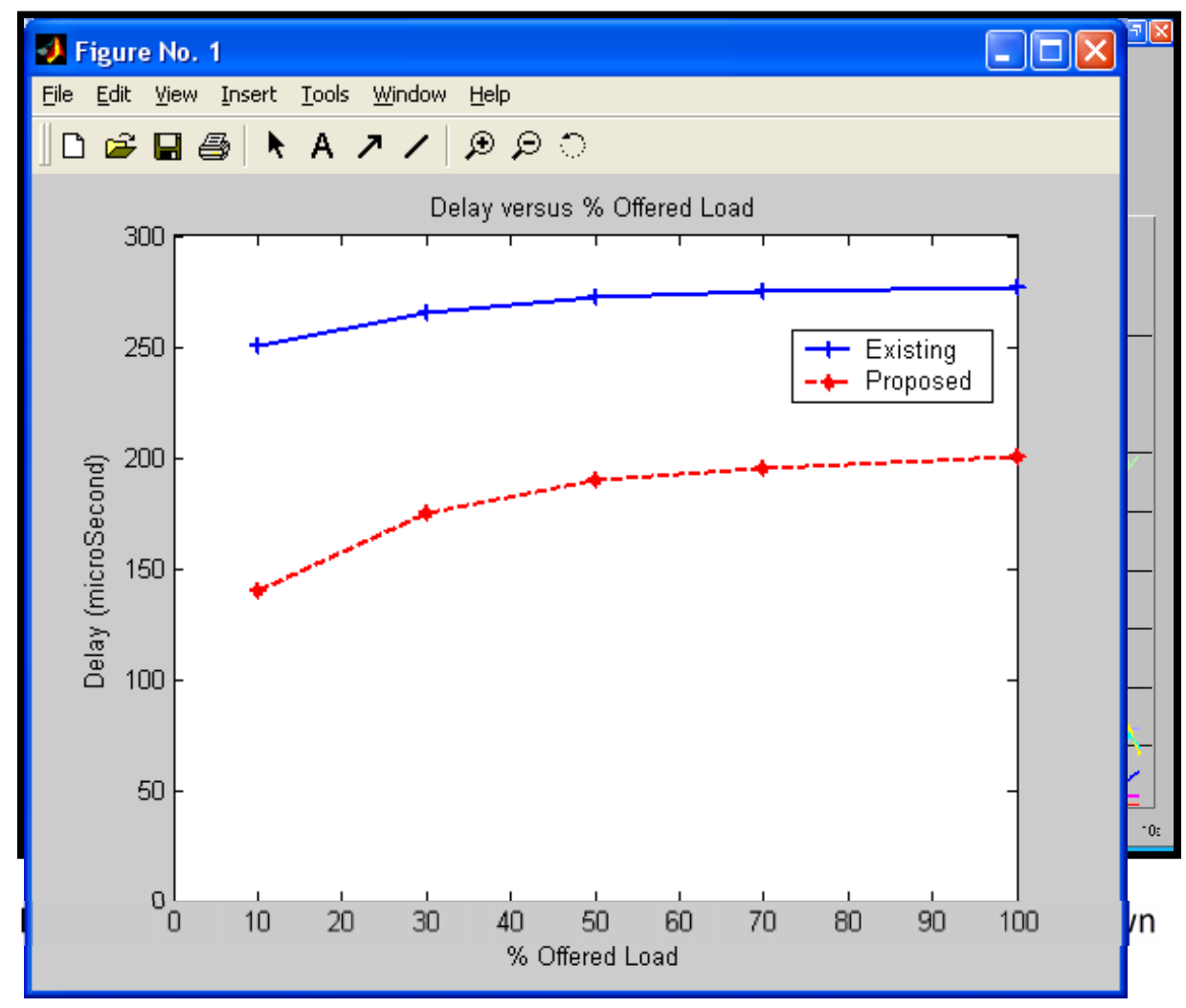

Figure (11). Node delay versus offered load.

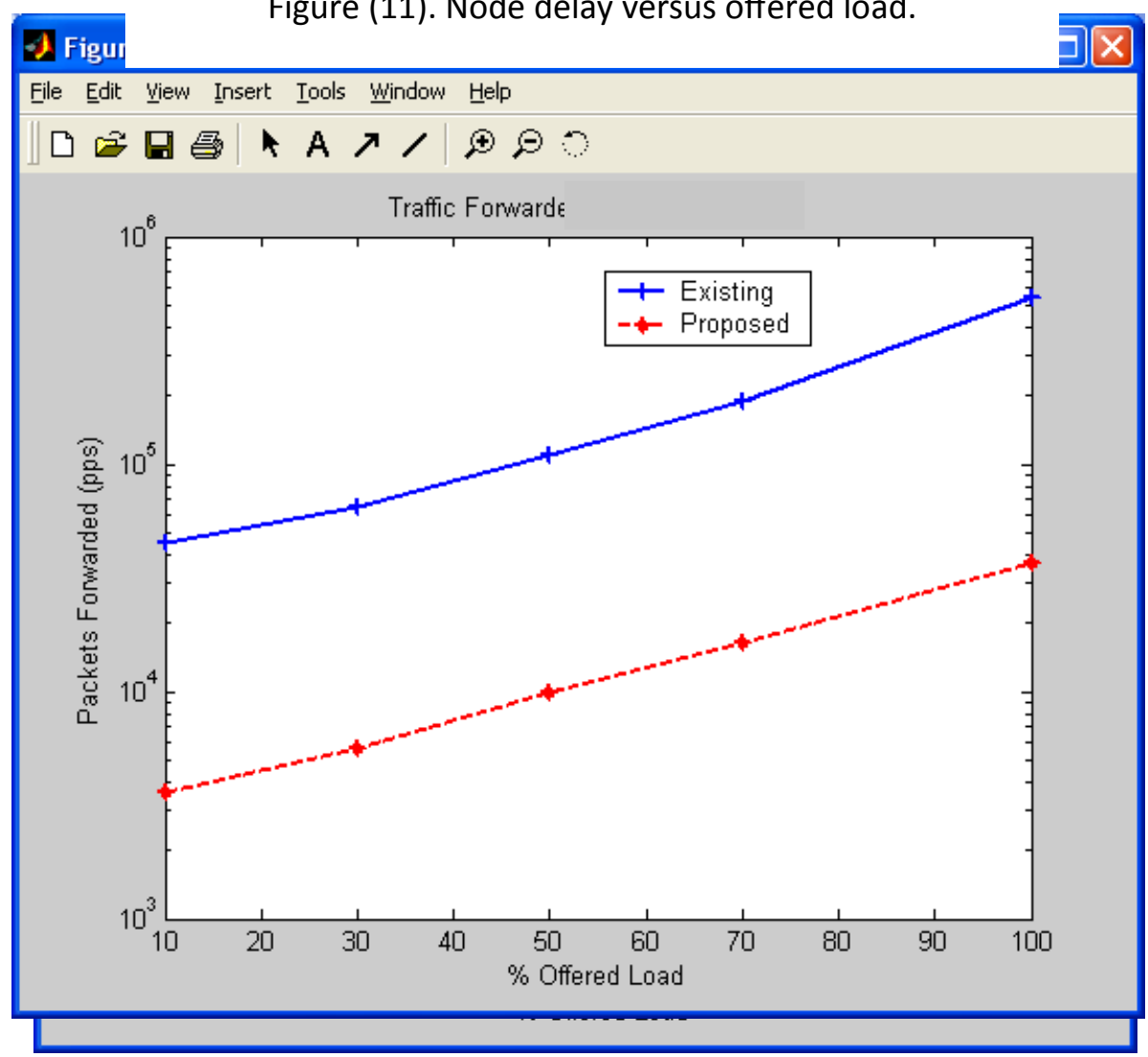

Figure (10). Traffic forwarded with respect to offered load as drawn by MATLAB. 


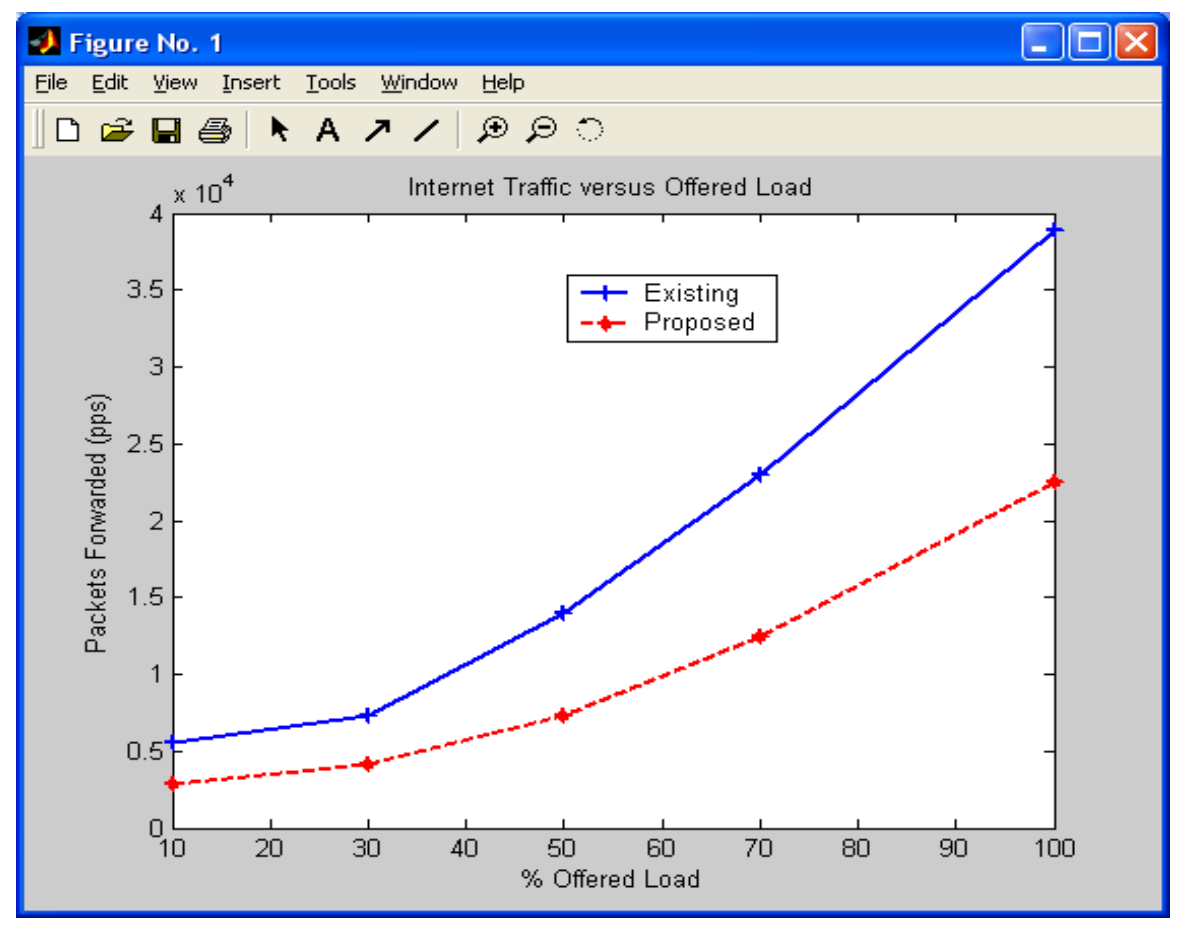

Figure (13) Internet traffic versus offered load.

\section{Conclusions:}

The results obtained in this paper show that the application of VLAN concept helps in decreasing unnecessary traffic, node delay, and increasing network throughput. This is due to segregating the single large broadcast domain that exists now into multiple limited broadcast domains for each VLAN. A delay performance improves by more than $25 \%$ with the use of VLAN technique and the throughput has doubled especially for large offered load. On the other hand, simulation study shows that Internet traffic decreased to approximately half that of the existing LAN.

\section{References:}

1. Xinjie Chang, "Network Simulations with OPNET", Proceedings of the 1999 Winter Simulation Conference, P. A. Farrington, H. B. Nembhard, D. T. Sturrock, and G. W. Evans, eds.PP 307-314.

2. WWW.OPNET.COM 
3. G. F. Lucio, M. P. Farrera, E. Jammeh, M. Fleury, and M. J. Reed, "OPNET Modeler and Ns-2: Comparing the Accuracy Of Network Simulators for Packet-Level Analysis using a Network Testbed", http://privatewww.essex.ac.uk/ fleum/weas.pdf

4. C. Burns, and K. Shaw, "Network Management", Network World, 28/2/2005, http://www.nwfusion.com/best/2005/022805tests3.

5. D. Passmore, and j. Freeman, "The Virtual LAN Technology Report", 3COM White paper, 1996. 